\title{
SYSTEMIC APPROACH FOR HISTORICAL MONUMENTS MAINTENANCE DECISION SUPPORT
}

\author{
Mirosław Dytczak \\ AGH University of Science and Technology \\ Kraków, Poland \\ E-mail: mdytczak@gmail.com \\ Grzegorz Ginda \\ AGH University of Science and Technology \\ Kraków, Poland \\ E-mail: gg.ginda@gmail.com
}

\begin{abstract}
Public financial resources are necessary for providing different economic, social, cultural and environmental services for the society. Note, that current troubles appearing in world-wide economy result in the severe limitation of availability of financial resources. Appropriate level of provision of public services is thus threatened. Historical monuments are example of objects that provide very specific services. Peculiar nature of the monuments makes their maintenance expensive, however. The implementation of efficient management of historical monuments becomes necessary, therefore, to provide the best possible effects while including limited resources. The management efficiency can be improved by means of identifying possibilities of providing additional financial resources by historical monuments. Such resources would facilitate maintenance of the monuments and help in maintaining other monuments. Note, that historical monuments are in general considered incomparable. However, the limited availability of financial and other resources results in the qualification of the selected historical monuments only for the conservation and the maintenance. Thus, the necessity of monument valuation arises. Diversity of monument attributes requires application of the systemic, intangibility-aware approach in this regard. The appropriate approach is presented in the paper.
\end{abstract}

Keywords: historical monument, management, support, decision, economy, financing, intangibles, DEMATEL, AHP/ANP. 


\section{Introduction}

Global and regional economic troubles result in the limited financial resources for public services. The services deal with diversified dimensions. For example, the service dimensions cover economic, social, environmental, cultural and other activities. The specific goals are also considered in this regard. The goals may be both tangible and intangible. Public services are usually prioritized while allocating limited financial resources. Some public services, that do not provide the economic efficiency, become then evidently less favored. Note, that historical monuments mainly provide cultural and social services only. As a result they generate costs and thus the maintenance of historical monuments belongs to the less favorable services. Therefore, the position and even the existence of the historical monuments is threatened by the limited amount of available resources.

Efficient spending of limited resources requires prioritization of historical monuments. The prioritization is based on the process of the monument valuation. Different monuments are usually deemed incomparable while valuating them. Note, however, that in practice, they are being prioritized while qualifying them for the conservation and maintenance. All essential monument attributes should be included to make the results of the valuation process adequate. The attributes can also depend on each other. The systemic approach should be then applied to valuate monuments in a proper way.

The historical monuments are generally capable of generating additional benefits and even financial resources when they appropriately utilised. The benefits may result from direct and indirect monument influence. The direct influence may for example deal with admission fees. It is related to the monument only. The indirect influence may cover the benefits both for the adjacent and more distant surrounding environment. Such influence mainly pertains to touristic traffic, and the related hospitality services. Note, that such activities result in the revival in the local and regional economy and society. The revival brings, thus, both tangible and intangible effects that should be included while valuating the historical monuments.

The appropriate approach for supporting decisions related to the maintenance of the historical monuments is presented, therefore, in the paper. The approach addresses the mentioned issues. The merits of the approach depend on applied valuation procedure. Therefore, the special attention is drawn to the issue of the determinants of historical monuments and the implementation of the procedure.

\section{The valuation of historical monuments}

The first attempts to valuate historical monuments took place in the beginning of the $20^{\text {th }}$ century (Riegl, 1903). The concept of the valuation changed from that time. It deals now with the notion of sustainable conservation that emphasizes the role of diverse stakeholders in the valorization procedure. The contextual differences in the meaning of different historical monument attributes were also included. The disputes about the value 
judgments and their relations to contextual cultural heritage and authenticity resulted in new issues related to the historical monuments valuation. The intangible heritage, technological heritage, nature heritage, spatial planning, globalization and cultural tourism were developed in this regard (Mason, 2002).

It proves that the appropriate valuation of historical monuments is a hard task. This is mainly because the term "value" is relative. It deals, for example, with the message of the artwork or the esteem it is held in. The relativity of value results from the possibility of the application of both the real and supposed worth, as well as, the significance or function of things while valuating them (Szmelter, 2010). The value becomes then a term that is susceptible to subjectivity of personal judgements. This is the real problem as such subjective approaches are usually utilized to valuate historical monuments. Application of objective multi-criteria decision tools (MCDA) is thus advisable to improve the valuation of the historical monuments.

Note, that structures of monument attributes are usually applied while valuating historical monuments. Availability of such data facilitates the utilisation of MCDA methods. However, there is a lack of one universally recognized attribute set (Skłodowski et al., 2012). For example, Mason (2002) divides monument attributes into 3 groups:

1. Intrinsic (authenticity - material, ancientness).

2. Extrinsic (socio-cultural - historical, cultural/symbolic, social, spiritual/religious, aesthetic, economic - market value, non-market value, existence, option, bequest).

3. Externally generated (economic externalities, social externalities).

The attributes that pertain to risk management, structural and material assessment are also often applied in this regard. Note, that the presented attributes are often intangible.

The monument attributes may also result from the existing law regulations. For example, the so called white card system (Skłodowski te al., 2012) is applied to document historical monuments in Poland. Availability of such regulations facilitates the monument valuation process.

\section{The valuation procedure}

Historical monuments are described by numerous attributes. The attributes belong to different dimensions. The following principal dimensions - attribute groups:

- historical features $(\mathrm{H})$,

- cultural features (C),

- social features (S),

- economic features (E),

- technological features (T),

- environmental features $(\mathrm{N})$

are usually recommended for holistic description of historical monuments (Fig.1). All relevant features should be then included to make historical monument valuation reliable. There appear several problems, however, that are related to the addressing historical monument features. Firstly, the multiplicity of the attributes makes valuation of the monuments a hard task. Therefore, the application of the key features only would facilitate reliable historical monument valuation. That is why the identification of the key historical monument features becomes the real necessity. The additional difficulty in the appropriate including of historical monument features results from different time and spatial contexts. This is because all the features should be considered in 3 dimensions. 
The dimensions deal with the past, the present, and the future. A local, regional, and national background ought to be considered too.

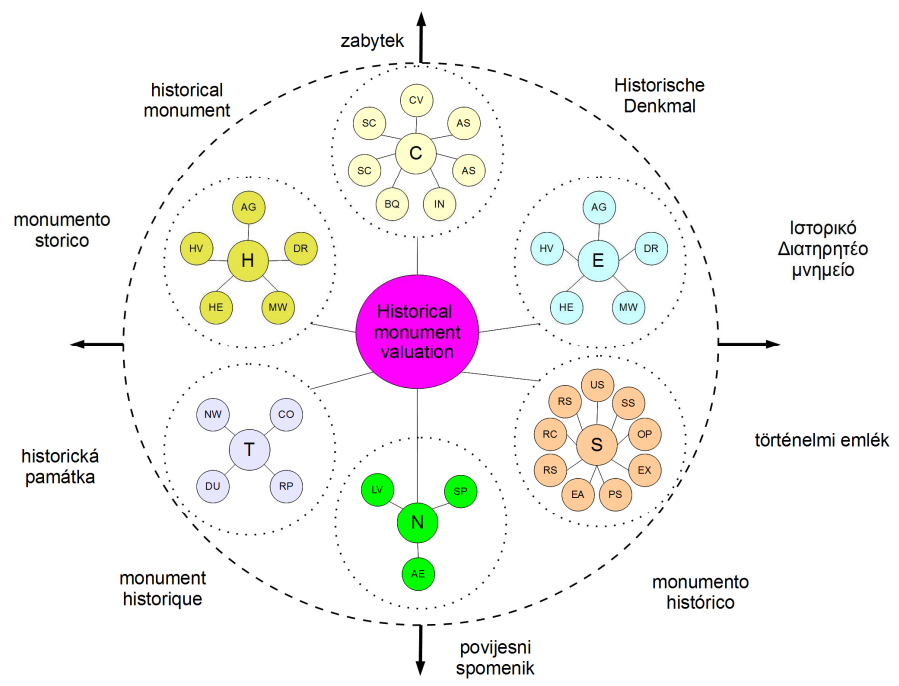

Fig.1. The multiplicity of historical monument features

Secondly, different dimensions of historical monument feature result in a need for using opinions of different stakeholders - both the specialized experts e.g. conservators, maintainers, users, technical personnel etc and society members. Applied valuation procedures should be then capable of aggregating assessments provided by different stakeholders.

Thirdly, the attributes may be of intangible nature. There may also appear feedback between the attributes (Fig.2).

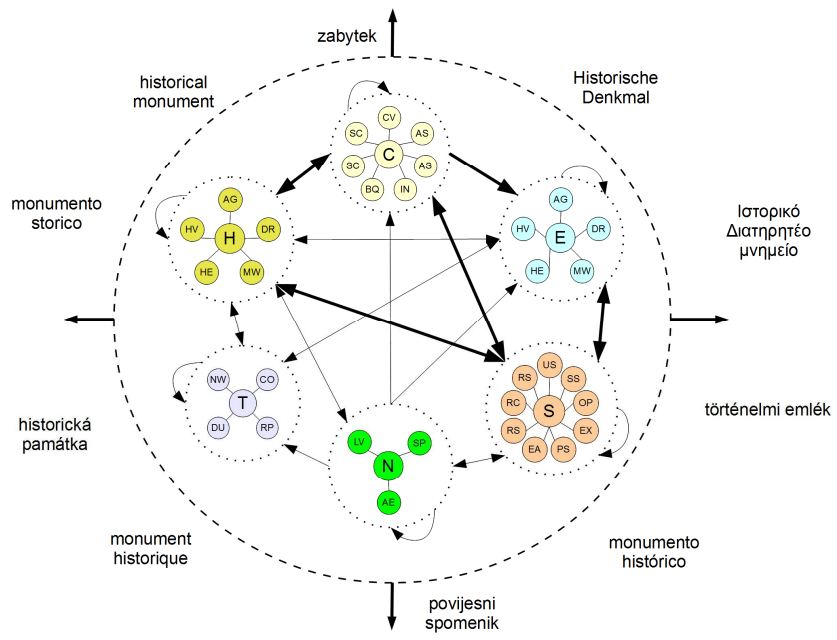

Fig.2. Different interactions between historical monument attributes 
Fourthly, historical monument features may differ in the influence on the overall historical monument value. Moreover, there may appear the differences between individual stakeholders and their groups or the differences between flavors of valuation approaches (and standards) with regard to historical monument feature influence assessment (Fig.3). These differences should be included, therefore, while valuating historical monuments to make valuation results reliable.

\section{Share of attribute groups}

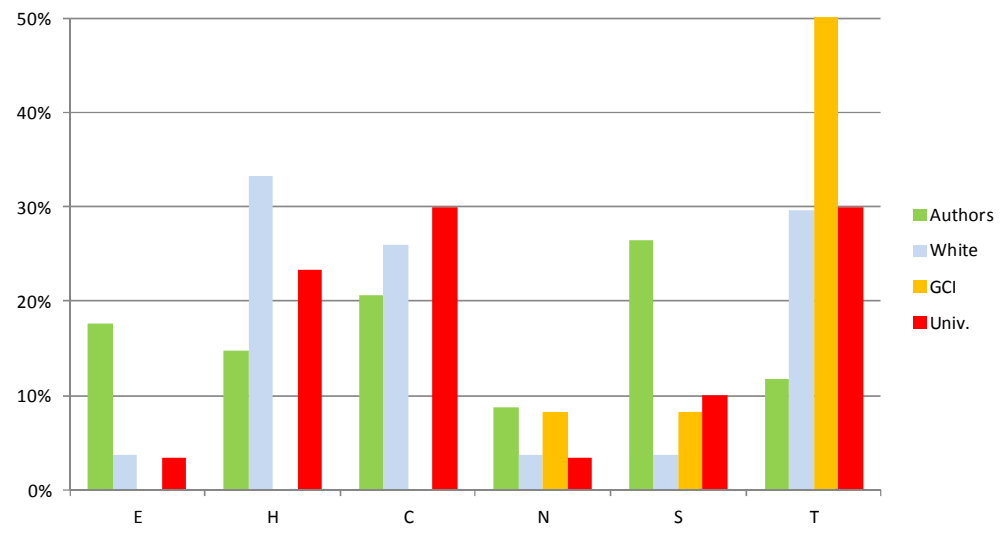

Fig.3. The differences in the feature influence assessments between valuation approaches

The valuation problems, mentioned above, make the reliable historical monument valuation a complex and difficult task. The application of appropriate tools would facilitate the task, however. Therefore, a valuation procedure that makes use of such tools is outlined next.

\section{Methodology}

The problems mentioned in the last section are dealt with application of AHP and support by DEcision MAking Trial and Evaluation Laboratory - DEMATEL (Fontela \& Gabus 1976). DEMATEL is suitable for the identification of the key monument features. But it is also applied for different purpose in the paper. It provides necessary means for the identification of interrelation structure between the key evaluation criteria in the proposed approach. Deterministic assessments are applied while defining direct influence between the evaluation criteria in DEMATEL.

The stakeholders involved in the valuation process comprise clusters. Each cluster consists of specific stakeholders e.g. conservators, users, maintainers, society members. Each stakeholder is confronted with a set considered set of evaluation criteria and historical monuments. He or she defines direct influence of evaluation criteria. Average direct influence matrix is then defined $\mathbf{X}^{*}$ (Fontela \& Gabus 1976) and DEMATEL is applied in an usual manner to assess the total influence of the criteria. Total influence matrix $\mathbf{T}$ is applied to express this information.

The matrix is then utilized to derive priorities for the criteria in an ANP-like manner. Firstly, $\mathbf{T}$ is normalised in a row-wise manner: 


$$
\underset{i=1,2 \ldots n}{\forall} \quad \bar{t}_{i j}=\frac{t_{i j}}{\sum_{k=1}^{n} t_{i k}},
$$

where $n$ denotes the number of applied evaluation criteria.

Secondly, ANP-alike stochastic supermatrix $\mathbf{S}$ is derived:

$\mathbf{S}=\overline{\mathbf{T}}^{\mathrm{T}}$.

The matrix is then risen to powers until it converges to obtain the limiting matrix $\mathbf{S}_{\mathrm{lim}}$ and to derive criteria priorities (Fig.4).

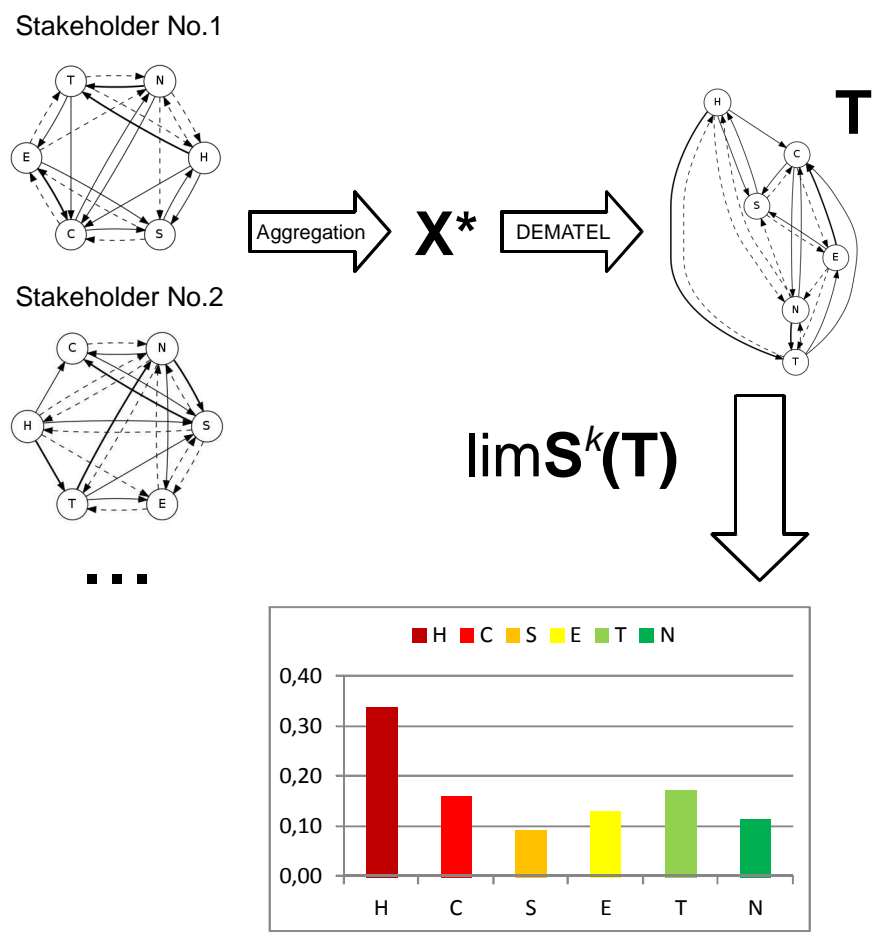

Fig.4. General scheme for deriving criteria priorities inside a stakeholders' cluster

Each stakeholder then compares valuated historical monuments in a pair-wise manner according to each criterion. Thus, partial monument rankings are derived. AHP rules and linear Saaty's scale are applied in this regard. Partial rankings are then aggregated using criteria priorities to obtain an individual ranking for each stakeholder.

The individual rankings are then combined by means of simple arithmetic average in the case of each cluster of stakeholders (Fig.5). Note that the perceived reliability importance of both individual stakeholders and clusters can be differentiated to facilitate making analysis outcomes more reliable. Weighted averaging can be applied in this regard.

Finally, the cluster-based rankings are aggregated (Fig.6). The final ranking provides necessary means to qualify the topmost historical monuments for financing and maintenance while considering limited amount of available resources. Note that usual AHP rules are applied while testing judgement consistency during calculations. 


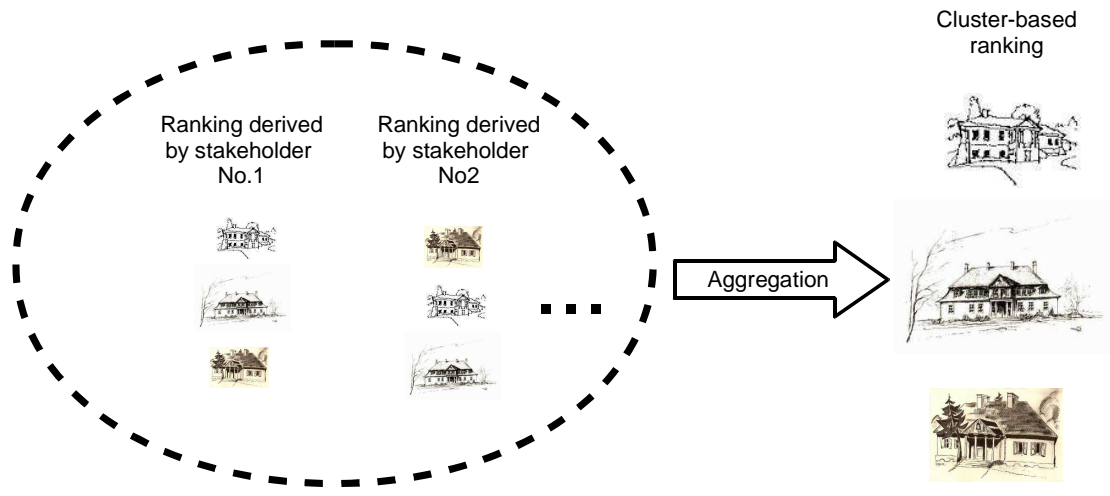

Fig.5. Internal cluster ranking aggregation

Final ranking

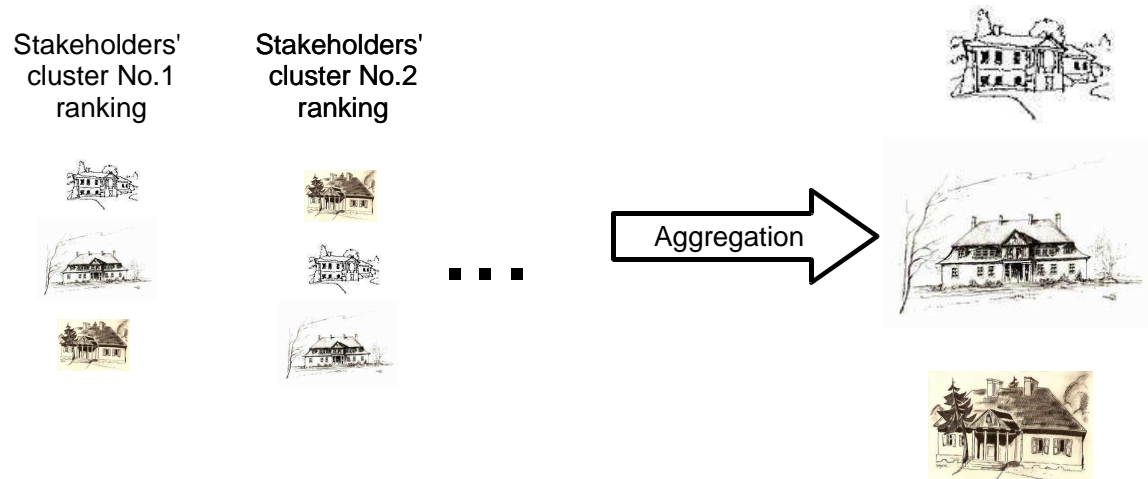

Fig.6. Cluster-wise ranking aggregation

\section{Analysis}

Let us consider two groups of stakeholders for illustrational purposes. The first group is consists of professional historical monument conservators and the second group consists of users who represent society member's interests. There are 3 different historical monuments considered. They are former local gentry residences: M1, M2, and M3. The analysis aims at the indication of the most valuable one. A standard set of general features presented in p. 3 is applied while valuating the monuments:

- historical features $(\mathrm{H})$,

- cultural features (C),

- social features $(\mathrm{S})$,

- economic features (E),

- technological features (T),

- environmental features $(\mathrm{N})$.

The opinions of two conservators are included. The 0-3 DEMATEL scale is applied by the professional conservators to construct a direct influence structure for a given set of valuation criteria. The structures of direct influence assumed by the conservators are presented in Fig.7. Differences in direct influence are expressed by line patterns of arcs. Bold line means direct influence level 3, solid line - level 2, and dashed line - level 1. 

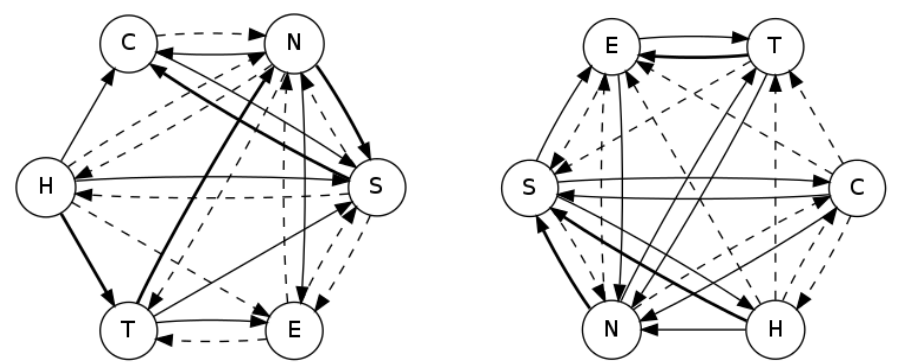

Fig.7. Direct influence structure provided by the conservators

The resulting average matrix of direct influence $\mathbf{X}^{*}$ (Fontela \& Gabus 1976) is presented in Eqn.3.

$$
\mathbf{X}^{*}=\left[\begin{array}{cccccc}
0 & 1.5 & 2.5 & 1 & 2 & 1.5 \\
0.5 & 0 & 2 & 0.5 & 0.5 & 1.5 \\
1.5 & 2.5 & 0 & 1.5 & 0 & 1 \\
0 & 0 & 1 & 0 & 1.5 & 1.5 \\
0 & 0 & 1.5 & 2.5 & 0 & 2.5 \\
0.5 & 1.5 & 3 & 1.5 & 1.5 & 0
\end{array}\right]
$$

Application of casual DEMATEL scheme leads to the total influence matrix T:

$$
\mathbf{T}=\left[\begin{array}{llllll}
0.127 & 0.379 & 0.579 & 0.375 & 0.365 & 0.431 \\
0.135 & 0.169 & 0.408 & 0.221 & 0.165 & 0.311 \\
0.229 & 0.409 & 0.288 & 0.324 & 0.161 & 0.313 \\
0.062 & 0.122 & 0.277 & 0.156 & 0.235 & 0.287 \\
0.092 & 0.181 & 0.407 & 0.434 & 0.158 & 0.436 \\
0.168 & 0.361 & 0.579 & 0.387 & 0.300 & 0.270
\end{array}\right] .
$$

The resulting priorities for the criteria are presented in Fig.8.

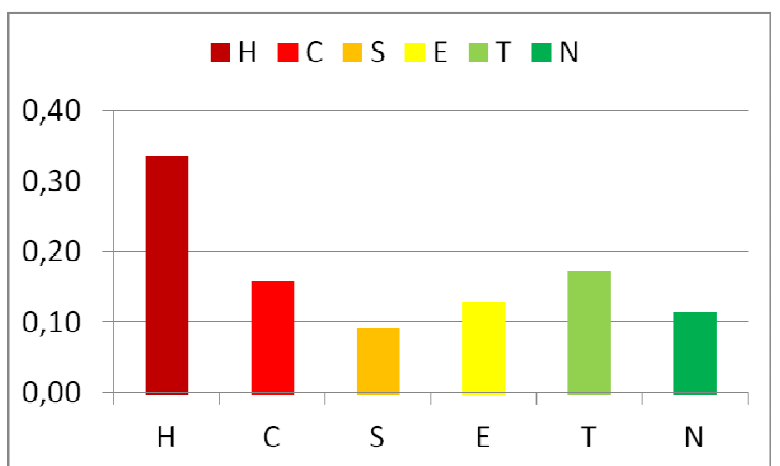

Fig.8. The normalised priorities for the criteria (the conservators' opinions) 
Partial and overall priorities for historical monuments derived by both conservators are presented in Fig.9. Simple arithmetic average is applied to aggregate partial priorities for historical monuments.
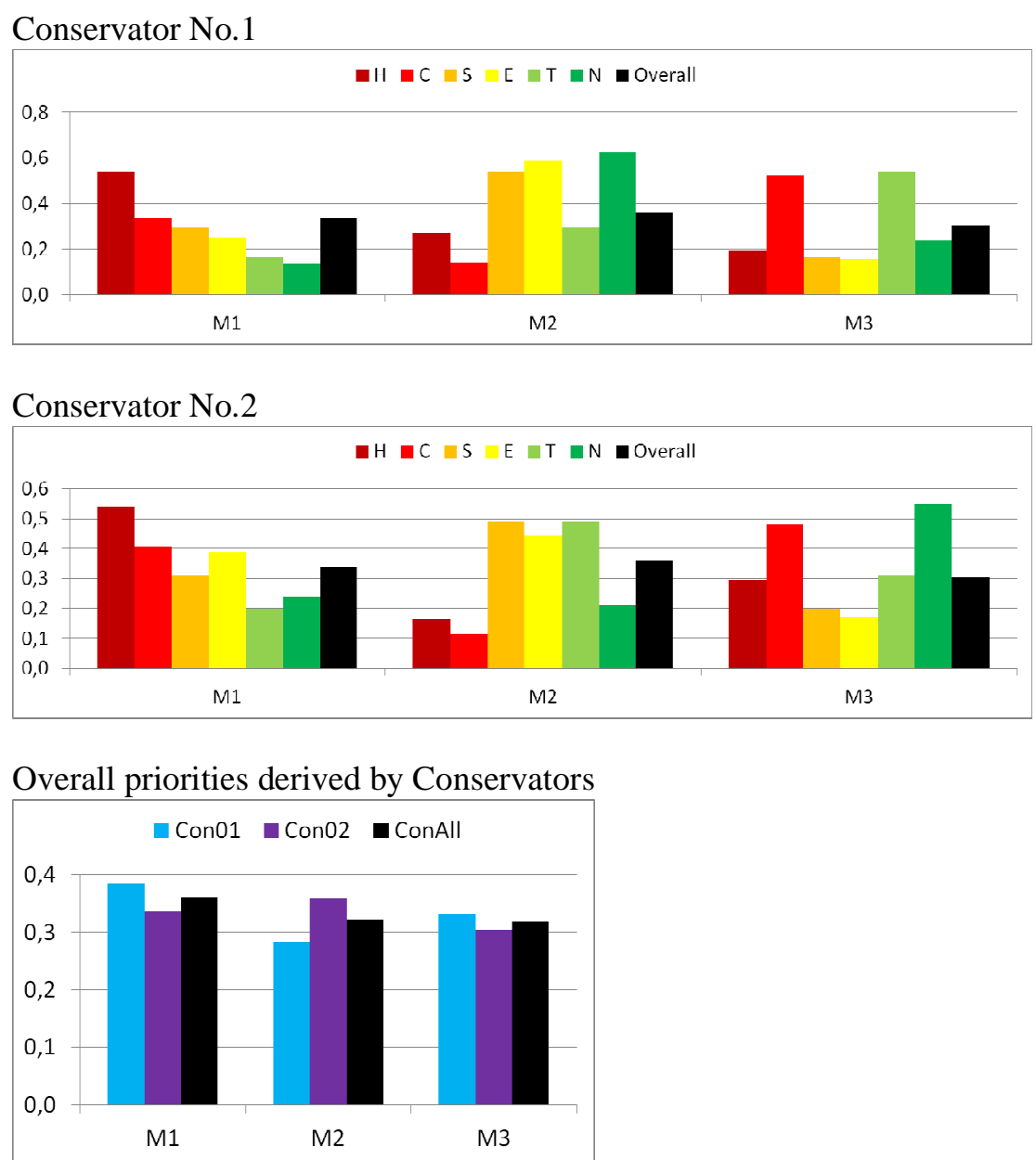

Fig.9. Priorities for historical monuments derived by the conservators

Priorities for evaluation criteria and historical monuments are derived in the similar manner in the case of society members (Fig.10).

It is evident that despite individual differences, all considered historical monuments are evaluated almost equally. The M1 seems the most valuable, however. It qualifies, therefore, for financial support. But M2 and M3 monuments prove, nevertheless, worth of finding support for their maintenance as well.

\section{Limitations}

Note that validity of valuation results depends on reliability of opinions provided by the appointed stakeholders. It seems that the application of an official expert registry would help in the selection of the appropriate opinion givers. It may turn out the good investment in long time perspective. This is because the limited availability of financial 
resources and the urgency in maintaining historical monuments tend to occur more and more often.

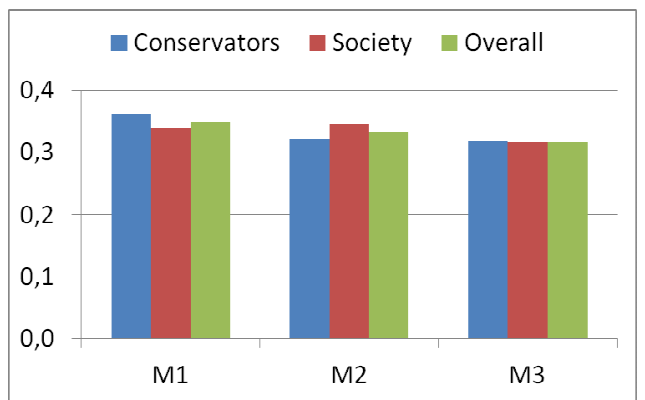

Fig.10. Aggregation of opinions of different stakeholders

\section{Conclusions}

The proposed approach provides the necessary means for the objective valuation of historical monuments because it addresses intangible nature and feedback between historical monument attributes. The approach makes use of DEMATEL to quantify the interrelations between the criteria. Note that DEMATEL is also applied to prioritise the attributes. It is also noticeable easier to use and less demanding tool than other decision support techniques which are capable of including feedback between the attributes. Therefore, utilisation of DEMATEL makes valuation of historical monuments easier. Its flexibility makes it a good complement for other decision support techniques. Results of the presented analysis confirm that it is capable of supporting the application of AHP too.

\section{Key References}

Fontela, E., \& Gabus, A. (1976), DEMATEL Observer, Geneva: Batelle Research Institute.

Mason, R. (2002), Assessing Values in Conservation Planning: Methodological Issues and Choices, in: de la Torre M. (Ed.), Assessing the Values of Cultural Heritage, Research Report, Los Angeles:The Getty Conservation Institute, 5-30.

Riegl, A. (1903), Der modern Denkmalkultus. Sein Wesen und seine Entstehung, Wien.

Skłodowski, M., Dytczak, M., \& Szmelter, I. (2012), In: Proceedings of Heritage Protection. From Documentation to Interventions, Volume: Proceedings of the EU-CHIC International Conference on Cultural Heritage, 191-192.

Szmelter, I. (2010), A New Conceptual Framework for the Preservation of the Heritage of Modern Art, Postprints of International Symposium Hoernemann Institute, in: Theory and Practice in the Conservation of Modern Art: Reflections on the Roots and the Perspectives, ARCHETYPE, London, 33-50. 